\title{
Author’s Reply
}

To the Editor,

We appreciate your interest in our paper entitled "Home blood pressure is the predictor of subclinical target organ damage like ambulatory blood pressure monitoring in untreated hypertensive patients" published in the December 2014 issue of Anatol J Cardiol (1).

1) In regression models, we used categorical variables for gender, smoking, diabetes, and dyslipidemia. On the other hand, we used numerical variables for blood pressure and age.

2) We are sorry, but we did not adjust for age and gender in comparing the prognostic significance of HBPM and ABPM.

Again, we thank you for your comments.

\section{Ae-Young Her}

Division of Cardiology, Department of Internal Medicine, Faculty of Medicine, Kangwon National University; Chuncheon-Republic of Korea

\section{References}

1. Her A, Kim YH, Rim S, Kim J, Choi E, Min P, et al. Home blood pressure is the predictor of subclinical target organ damage like ambulatory blood pressure monitoring in untreated hypertensive patients. Anatol J Cardiol 2014; 14: 711-8. [CrossRef]

Address for Correspondence: Se-Joong Rim, M.D., Ph.D., Division of Cardiology, Department of Internal Medicine, Faculty of Medicine, Kangwon National University, Chuncheon-Republic of Korea

Phone: (82-2)-2019-3336

E-mail: hermartha1@gmail.com 